\title{
Health Care Provider Value Chain
}

\author{
Lukasz Kawczynski and Marco Taisch \\ Department of Management, Economics and Industrial Engineering, \\ Politecnico di Milano, \\ Piazza L. da Vinci, 32 I-20133 Milano, Italy \\ \{lukasz.kawczynski, marco.taisch\}@polimi.it
}

\begin{abstract}
In every society there is a need for an efficient health care system. This paper aims to propose a value definition and a value chain model within the health care. In order to define value patients and experts were surveyed. The proposed definition offers a complex way of looking at the value within the health care sector. The proposal of the value chain model is anticipated with a value stream mapping activities and experts interviews. Proposed model offers consistent way of looking at the value chain from health care provider perspective.
\end{abstract}

Keywords: Health care, Value Chain Model, Value Definition.

\section{Introduction}

In nowadays of a high competitive market, companies compete by creating more efficiently a greater value for customers. The way to create a value for a customer is through an efficient, well organized value chain, and an understanding of the mechanism supporting value creation process. Recently health care has been having a lot of problems in many countries and at the same time is a strategic sector for every economy. This paper is part of larger research and is providing a summary of the value chain and value investigation performed so far. The research aims to investigate US healthcare value chain with a focus on operational perspective. The ultimate goal is to offer value definition within health care, health care provider value chain, and support it with a simulation model. The paper offers a consistent value chain model and a complex value definition. Good quality value chain model with a focus on health care provider perspective has not yet been proposed in the literature. Proposed definition is enhancing current understanding of value within health care.

\section{Literature Review}

There are three streams that should be reviewed under this section: the value chain within the health care, value definition, and as a linked, subject patient satisfaction mechanism. Many authors were defining and discussing concepts of value. Mostly the concept of value was discussed based on manufacturing environment, although some of the authors took an attempt to focus on services. [8] defined value as a utility combination of price and non-price benefits offered to the consumer. The author admitted 
as well that a value is a relative measure that each consumer determines by comparison of product with similar market offerings. [10] defined value as a result of products or service's ability to meet a customer's priorities. As an alternative, [5] offered a value equation concept one of the few authors who took an attempt to define a value within health care was [12]. Authors defined value as benefits and costs for patients and the internal activities or processes necessary to produce benefits for the patient. [9] focused strictly on patient value as a health outcome achieved per dollar of cost compared to peers.

The direct consequence of value perceived is a satisfaction. The commonly used indicator that utilizes customer expectations, customer satisfactions, and customer loyalty intentions is Customer Satisfaction Index (CSI), [4]. The CSI is a structural model based on the assumptions that customer satisfaction is caused by some factors such as perceived quality (PQ), perceived value (PV), expectations of customers, and image of a firm. One way of measuring PQ is SERVQUAL a framework introduced by [6]. SERVQUAL is the most prominent and widely used model for measuring service quality. [3] proposed alternative tool to SERVQUAL dedicated for healthcare. [11] developed and empirically tested a model to examine the major factors affecting patients' satisfaction that depict and estimate the relationships between service quality, patient's emotions, expectations, and involvement.

Each company, whether representing a manufacturing or service sector, satisfies customer and delivers a value to the customer through the value chain. The concept of the value chain was first introduced in the literature by [7]. The value chain was defined as an entire production chain from input of raw materials to the output of final products consumed by end user. [2] proposed concept dedicated for health care named continuum. Under this concept there is neither a beginning nor an end - all the stages and activities are continuously performed. [1] offered in his book a general model of value chain dedicated for health care. The model is consisting of five different parties (payers, fiscal intermediaries, providers, purchasers, and producers).

Many authors were taking an attempt to provide value chains for different industry sectors. Manufacturing industry was the most studied. Few value chains with different perspectives were proposed for health care.

\section{Methodology}

The current paper is divided into two parts. The first part aims to propose a value definition based on patients' surveys and interviews with experts, while the second part aims to propose a consistent value chain model based on process mapping activities.

In order to understand the value mechanism we ran patient satisfaction survey. On selected days, before the medical appointment, patients were asked to complete a survey and returned it in the enclosed envelope. Three hundred and thirty valid responses were received. The survey tool was divided into five subsections (access to care, experience during the visit, opinions about care provider, personal issues, and overall assessment). Each group was containing questions regarding the satisfaction / perceived value within particular area of health care provider activity. With 42 
questions, on a five point Likert scale (very poor, poor, fair, good, and very good) patients were asked to express their opinion. Additionally, patients were asked to answer three supportive questions. First question was asking if this was the patients first visit at this particular clinic, while the second and third were asking about the waiting time before the patient was called to the exam room and time spent in the exam room. This tool allowed us to survey for patient satisfaction and consequently for the value perception. Moreover, to enhance value understanding we conducted interviews with experts. We interviewed appropriate process owners. The interviews were not structured and are rather having an open form and are aiming to exhibit how each process creates a value (if any) and how this value can be better created for patient.

The second part aims to propose a value chain model. The analysis started with drawing value stream map for the clinic. Both process owners and shop floor workers were interviewed. The final value stream map was evaluated by process owners (supervisors and managers of particular sections). The value stream map provides us with information on the processes that are involved in value creation mechanism for the patient. Based on the map we divided processes into logical groups, in order to be able to accommodate them within the value chain model. The value stream map with the support of the interviews with the experts provides a base for proposing a value chain model.

\section{Health Care Provider Description}

The health care provider taking part in this research is specialized in children care. The provider is operating through the chain of clinics all over east and south US. The studied clinic has 13 sub-clinics representing different specialties. The provider operates from 8 AM to 4 PM, Monday through Friday. The clinic serves on average 93 patients daily, which makes it a medium size health care provider.

\section{Patient Value}

The patient value analysis started with the survey of patients. Within the survey $28 \%$ of respondents were new patients. $48 \%$ of patients were waiting between 0 and 5 minutes after scheduled appointment time to be called to the pre-examination room. Respectively, $27 \%$ were waiting 6 to 10 minutes, $10 \%$ - 11 to 15 minutes, $10 \%$ - 16 to 30 minutes, and $4 \%$ were waiting more than 31 minutes. In the exam room $63 \%$ of patients were waiting less than 5 minutes for care provider, while $18 \%$ were waiting between 6 and 10 minutes. Remaining $20 \%$ of patients were waiting more than 11 minutes. In order to provide statistical analysis we have assigned to each of the points on Likert scale a value from 0 (Very poor) through 50 (fair) to 100 (very good). This converts responses into five values interval variable. The questions were assigned to five groups in order to be analyzed. The clinics overall facility rating mean was found to be 90.7. The subsections scores are exhibited in statistic summary in Table 1. 
Table 1. Survey groups summary.

\begin{tabular}{lcc}
\hline Questionnaire group & Mean & Standard deviation \\
\hline Overall facility rating & 90,7 & 10,8 \\
Registration & 91,5 & 11,8 \\
Facility & 89,2 & 14,5 \\
Treatment & 91,9 & 11,7 \\
Personal & 91,5 & 11,3 \\
Overall assessment & 94,0 & 10,8 \\
\hline
\end{tabular}

The first step was the correlation analysis. There was significant correlation found between overall respondent satisfaction and particular questions within the subsections. This suggests that certain factors are more important than others in the satisfaction (value) mechanism. The 22 out of 43 questions with the highest correlation coefficients are exhibited in Table 2.

Table 2. Top correlation coefficients questions

\begin{tabular}{|c|c|c|c|c|c|}
\hline No. & Question & $\begin{array}{l}\text { Correlation } \\
\text { coefficient }\end{array}$ & No. & Question & $\begin{array}{l}\text { Correlation } \\
\text { coefficient }\end{array}$ \\
\hline 1 & $\begin{array}{l}\text { Courtesy of person that } \\
\text { scheduled appointment }\end{array}$ & 0,79 & 12 & $\begin{array}{l}\text { Helpfulness of } \\
\text { registration person }\end{array}$ & 0,71 \\
\hline 2 & Overall rating of care & 0,76 & 13 & Concern for privacy & 0,71 \\
\hline 3 & Precautions for safety & 0,76 & 14 & Degree of safety and sec. & 0,71 \\
\hline 4 & Staff concern for worries & 0,75 & 15 & Ease of moving around & 0,70 \\
\hline 5 & Team work of staff & 0,75 & 16 & Ease of registration & 0,70 \\
\hline 6 & Staff concern for comfort & 0,75 & 17 & Ease of scheduling & 0,70 \\
\hline 7 & Comfort of waiting area & 0,74 & 18 & $\begin{array}{l}\text { Effort of staff to } \\
\text { introduce themselves }\end{array}$ & 0,70 \\
\hline 8 & $\begin{array}{l}\text { Concern for child's } \\
\text { comfort }\end{array}$ & 0,73 & 19 & Courtesy of medical staff & 0,69 \\
\hline 9 & Sensitivity to your needs & 0,73 & 20 & Cleanliness of facility & 0,68 \\
\hline 10 & Friendliness of staff & 0,72 & 21 & Skills of staff & 0,68 \\
\hline 11 & Response to concerns & 0,72 & 22 & Explanation given & 0,68 \\
\hline
\end{tabular}

The highest correlation coefficient was found between the overall satisfaction and a courtesy of personnel scheduling the appointment $(0,79)$. The second highest correlation coefficient was found to be overall rating of care. This question describes how the medical side of the appointment is assessed by a patient. Within top ten questions with the highest coefficients we might notice that most of them are the questions concerning staff behavior (courtesy, friendliness, concern). Out of the top ten questions the only ones that are not addressing staff behavior are questions 2, 3, and 7. This confirms that the very important aspect within patient quality (and consequently shaping perceived value and patient satisfaction) is human interaction factor. This seems to put in doubt the definition of value within a health care proposed by [9], as it assumes that the important factors are medical benefits and cost. This definition abandoned completely the way how the medical benefits are delivered (human factor). The correlation table reveals as well importance of process and facility related factors. 
Among others are degree of safety and security felt, ease of finding your way around, ease of the registration process, ease of scheduling appointment, cleanliness of facility, and waiting times. Most of these factors could be assign as well as a group that explains the way the service was delivered, while waiting times are related to the cost of obtaining a medical service.

The interviews with the experts included five interviews with supervisors and middle level managers. The interviews were having an open form, with questions regarding how patients perceived value, how patients' satisfaction is achieved, and what processes are involved in the value creation process. Four out of five respondents were highlighting an importance of medical outcomes in the satisfaction (perceived value) mechanism. The medical outcomes were pointed to have two meanings. Medical outcomes defined as an improvement of medical status (recovery) and change in the patient's awareness about sickness. Interviewee were pointing out that usually the first aspect is not fully in control of the health care provider, as it takes time, might be influenced by other providers and physically happens outside the clinic. The interviewees were stretching the importance of perceived value as a direct indicator of patient satisfaction and loyalty. Moreover, the cost of the medical appointment, especially for self paying patients and partly for insured patients (co-pay), was mentioned as secondary factor influencing patient perceived value and consequently satisfaction.

Additionally, according to American Customer Satisfaction Index framework the important factor influencing a customer satisfaction and perceived value are the expectations. Based on the patients and experts surveys ran within studied case and investigation of ACSI we took an attempt to formulate a value definition within the health care as a relation of medical recovery progress or acknowledge of medical state, under the way the product and / or service was delivered, to the expectations, time, and overall costs associated with obtaining medical products and / or services received. The proposed definition offers a complex way of looking at the value within the health care and at the same time enhances quality of proposed definitions within literature. For the first time the proposed definition takes into consideration medical acknowledgements as a factor that brings value, expectations, time, and overall costs associating with obtaining the medical product or service. Additionally, the definition points out that the care provider can influence the value perceived by the patient by the way products or services were delivered.

\section{Value Stream Mapping}

For the purpose of value chain analysis we ran a value stream mapping. The value stream mapping revealed a process that has a few variations. The variations are caused among others by sickness type, payer type (self paid, insured, and underinsured patient) or whether it is a new patient or returning one. The whole value stream flow is centralized around a patient management system (PMS), which keeps patients' medical history file, stores referrals, and provides appointment scheduled. The main processes brining a value that were identified are:

1. Pre-registration - gathers data from the guardian (medical history, reason for a visit, insurance data). The insurance is verified and data documented in the PMS.

2. Scheduling - provides patient with a suitable opening. 
3. Check-in - provides final verification of the data in the PMS (names spellings, addresses, and contact information), verifies insurance and let processes downstream know that the patient arrived in the clinic (through PMS).

4. Pre-examination - verifies patients medical record and gathers basic vitals (weight, height, temperature and in some cases blood pressure).

5. Medical exam - based on medical history file (located in PMS), additional tests, labs (if required), and physical exam provides diagnosis.

6. Check-out - closes in the system the patients' medical appointment.

Each of the processes of the value stream has its own laws, regulations, and institutions external interaction. The process and personnel executing the process has to comply with various regulations and laws (for instance HIPAA).

The value stream map has a couple of interactions with external entities that are being part of the value creation process. These units are not part of the clinic itself, but are involved in value generation process: payors (for instance insurance companies), referring physicians (if any), external laboratories (when needed), and external health care provider (for additional consultations if needed).

\section{Value Chain Model}

The value stream analysis is a base for development of a value chain model. The model provided by Porter in 1985 was used as a framework. The main processes bringing value from the patient point of view are pre-registration, scheduling, checkin, pre-examination, and medical examination. It is essential to notice that for an insured patient, billing does not bring itself a value, although could be classified as a value adding process. Patient is not involved in billing processes and in fact is not even aware how this process is working. However, the important issue for a patient is the fact that the care provider is accepting the insurance policy, which is verified during pre-registration, and later on during check in. In order to be able to accept insurance policy, the care provider has to have a contract with the payor. This reasoning led to the conclusion that sales and contracting is an important part of the value creation process. The process itself is executed before actual interaction of the clinic with the patient begins. Moreover, as pointed out by experts during value definition phase, the health problems are requiring supervision over the recovery process. It is executed by follow up appointments and makes the recovery and follow up from the patients' point of view, a process that brings a value. The first moment, when the value might be created for a patient, starts actually before sales and contracting. The marketing and patient education done by health care provider brings a value for a patient. Through this processes patients are gaining knowledge about available treatments, sicknesses, threats, new diseases, preventive actions, and health care providers available on the market. Some of the value creating processes might be performed partly or totally outside clinic boundaries. The service delivery itself might be done partly outside boundaries of health care provider by referring patient to external laboratories. The same situation might occur with follow up and recovery. The patient might decide to be seen by a different care provider that is not part of the clinic that the medical treatment was started in. Interestingly, marketing and education processes might also be influenced by the activities of companies not depending on health care 
provider. For instance, education efforts done by competitors, trying to create patient awareness of crone diseases might bring a patient to a totally different health care provider than the one that was running the advertising campaign.

For proposing a value chain model we used Porter's model as a frame. The generic support activity categories do not require modifications for health care, as they are the same as Porter's (infrastructure, human resource management, development and innovation, and procurement). The primary activities are going to be changing depending on the payor type. In case of insured patients (the most common case), the primary activities are going to be: marketing \& patient education, sales \& contracting, pre-registration, scheduling, service delivery, and recovery and follow-up. Some of the primary activities will be influenced by the forces being located outside provider's boundaries as exhibited in Figure 1. For the simplicity of the drawing we accumulated check in, pre-examination, medical examination, and check out into service delivery block.

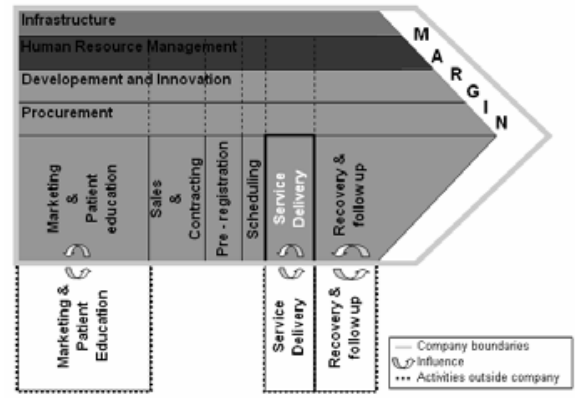

Fig. 1. Proposed value chain model (insured patients).

In case of the uninsured patients, the value chain model is going to differ than the one in Figure 1. The modifications will be a consequence of presence of different payors. The sales and contracting activities are not going to be a part of the primary activities.

For underinsured patients - the patients that are not able to afford medical bills or insurance, the value chain model is going to differ than the one for uninsured patients. The financial counseling activity with financial aid assistance will be an additional primary process bringing value. The three models of value chain are offering consistent way of looking at the value creation process from the health care provider perspective.

\section{Conclusion and Further Research}

The proposed definition of value within health care provides a new innovative way of looking at and analyzing a value (and consequently satisfaction) mechanism. The definition offers an incremental improvement comparing to the definitions dedicated for health care available in the literature, by considering additional factors. 
The value chain model provides differentiation that is dependent on payor type. The proposed model highlights phenomena of value creation outside boundaries of the health care provider, which is a new aspect that has not been yet proposed. These processes are very important from the patient perspective, since they are going to be associated in patients mind with main health care provider. In the past this issue has not been well discussed in the literature for health care.

This research has certain limitations that should be studied in the future with more details. The expectation, as an aspect influencing patient value perception should be researched more deeply by conducting a mutual survey of patient expectations and patient satisfaction. This would precisely picture how the medical experience (perceived quality) is shaping the satisfaction (and perceived value) and how the satisfaction is shaped by the expectations. Conclusively, although the models were internally validated, the research should be enhanced on other health care providers in order to ensure external validity.

\section{References}

1. Burns, L.R.: The health care value chain: producers, purchasers and providers. Jossey-Bass A Wiley Company, San Francisco (2002) ISBN: 0-7879-6021-7

2. Deffenbaugh, J.L.: Health-care Continuum. Health Manpower Management 20(3), 37-39 (1994), ISSN: 0955-2065

3. Duggirala, M., Rajendran, C., Anantharaman, R.N.: Patient-perceived dimensions of total quality service in healthcare. Benchmarking: An International Journal 15(5), 560-583 (2008)

4. Fornell, C.: A national satisfaction barometer: the Swedish experience. Journal of Marketing 56, 6-21 (1992)

5. Heskett, J.L., Sasser, W.E., Schlesinger, L.A.: The service profit chain: How leading companies link profit and growth to loyalty, satisfaction and value. The Free Press, New York (1997)

6. Parasuraman, A., Zeithaml, V.A., Berry, L.L.: SERVQUAL: a multiple-item scale for measuring consumer perceptions of service quality. Journal of Retailing 64(1), 12-40 (1988)

7. Porter, M.E.: Competitive advantage: Creating and sustaining superior performance. The Free Press, New York (1985)

8. Porter, M.E.: What is strategy? Harvard Business Review (November/December 1996)

9. Porter, M.E., Teisberg-Olmsted, E.: Redefining health care - Creating value-based competition on result. Harvard Business School Press, Boston (2006), ISBN13: 978-1-591139778-6

10. Slywotzky, A.J., Morrison, D.J.: The Profit Zone. Wiley, New York (1997)

11. Vinagre, M.H., Neves, J.: The influence of service quality and patients' emotions on satisfaction. International Journal of Health Care Quality Assurance 21(1), 87-103 (2008)

12. Walters, D., Jones, P.: Value and value chains in healthcare: a quality management perspective. The TQM Magazine 13(5), 319-335 (2001), ISSN: 0954-478X 